\title{
Bubbles and Overshooting Crash
}

\section{Li Dai' and Peng Zhou ${ }^{2 *}$}

${ }^{1}$ School of Economics and Trade, Hunan University, China

${ }^{2}$ Cardiff School of Management, Cardiff Metropolitan University, Cardiff, CF5 2YB, UK

\begin{abstract}
This paper reviews a model of bubbles under the assumption of heterogeneous rational traders. In the presence of dispersion of opinions, or sequential awareness, financial bubbles are justified by the interactions between rational arbitrageurs and behavioural traders. Timing is a very important component in the trader's strategy. This model is then extended to explain both bubbles and overshooting crash.
\end{abstract}

Keywords: Rational bubbles; Overshooting crash; Heterogenous traders; Timing strategy of trading

\section{Introduction}

Bubbles usually refer to asset prices that exceed the asset's fundamental value because current owners believe that they can resell the asset at an even higher price in the future. That is to say, the owners do not have to believe that the current price reflects the fundamental value. As long as there is enough absorption capacity in the market, a bubble can be persistent. However, classical models cannot explain the existence of bubbles, because if everyone knows that bubble will crash eventually, backward induction will leads to no bubble at all. This argument requires two things: all the traders are rational and the existence of bubble is common knowledge.

Bubbles are very often observed in economic history, such as the Dutch tulip mania of the 1630's, the South Sea bubble of 1719-1720 and more recently the Internet bubble in early 2000. Even Newton tried to ride the South Sea Bubble in 1720 . He got out of the market at $£ 7,000$ after making a $£ 3,500$ profit, but he decided to re-enter the market thereby losing $£ 20,000$ at the end. Frustrated with this experience, he concluded: "I can calculate the motions of the heavenly bodies, but not the madness of people." This essay reviews a model of "the madness of people" based on Abreu and Brunnermeier [1], and extends this model from explaining bubble to overshooting crash.

\section{Literature Review}

There are four main types of models that justify bubbles. The first class of models assumes that all investors have rational expectations and identical information. These models generate the testable implication that bubbles have to follow an explosive path. In the second category of models, traders are asymmetrically informed and bubbles can emerge under more general conditions because their existence need not be common knowledge. The third strand of models focuses on the interaction between rational and irrational (or behavioural) traders. Bubbles can persist since limits to arbitrage prevent rational traders from eradicating the price impact of irrational traders. Lastly, bubbles can emerge if investors hold heterogenous beliefs, potentially due to psychological biases or information availability. This section will focus on the following criteria to highlight the model proposed by Abreu and Brunnermeier [1].

- Whether existence of bubble is common knowledge;

- Whether all traders are rational;

- Whether there is capital constraints.
To start with, Milgrom and Stokey's seminal paper derives "No Trade Theorem" under classical framework. If all traders are rational and the fundamental value is common knowledge, then no one can profit from private information because private information is revealed by price changes. The efficient markets hypothesis implies the absence of bubbles [2]. Allen, Morris and Postlewaite [3] develop "Contra Positives" of the no trade theorem highlighting necessary conditions for the existence of bubbles. If all traders are rational, but only have mutual knowledge (not common knowledge), then bubbles may exist. Similarly, in Allen and Gorton [4], they argue if all traders are rational, but there is asymmetric information, better informed traders can "Churn Bubbles" at the expense of the less informed traders. These literature justifies bubbles by relaxing the common knowledge assumption. Similarly, in Abreu and Brunnermeier [1], there is heterogeneity among rational traders on when the bubble begins. Traders are aware of the existence of bubbles sooner or later, but they do not know if the others are already informed.

In Delong, et al. [5], rational arbitrageurs push up the price after some initial good news in order to induce irrational traders to aggressively buy stocks in the next period. This delayed reaction by the irrational traders allows the arbitrageurs to unload their position at a profit. This strand of literature justifies bubbles by relaxing the rationality assumption. Similarly, in Abreu and Brunnermeier [1], there is interaction between rational traders and irrational traders.

Another paper written by Delong, et al. [5] find that traders' risk aversion and short horizons limit their ability to correct the mispricing. Shleifer and Vishny argue that professional fund managers forgo profitable long run arbitrage opportunities because the price might depart even further from the fundamental value in the intermediate term. These literatures assume that rational traders do not have the collective ability to correct bubbles because of their risk attitude or exogenously binding capital constraint. In Abreu and Brunnermeier [1], however, the aggregate resources of all arbitrageurs are assumed to

*Corresponding author: Peng Zhou, Cardiff School of Management, Cardiff Metropolitan University, Cardiff, CF5 2YB, UK, Tel: 02920 688778; E-mail: pzhou@cardiffmet.ac.uk

Received November 17, 2016; Accepted December 17, 2016; Published December 22, 2016

Citation: Dai L, Zhou P (2016) Bubbles and Overshooting Crash. Bus Eco J 7 : 263. doi: $10.4172 / 2151-6219.1000263$

Copyright: (c) 2016 Dai L, et al. This is an open-access article distributed under the terms of the Creative Commons Attribution License, which permits unrestricted use, distribution, and reproduction in any medium, provided the original author and source are credited. 
be sufficient to crash the bubble. The existence of bubble does not rely on the limited financial ability of arbitrageurs.

\section{Assumptions}

Following the comparison with the related literature, the assumptions of the Abreu and Brunnermeier [1] model can be summarised as follows:

- Rational Traders interact with boundedly rational traders.

- A critical mass of traders is needed for a bubble to crash ("coordination").

- A proportion $(\mathrm{K})$ of traders are needed to correct the mispricing.

- There is a dispersion of opinion among traders (sequential awareness), so the timing is important ("competition").

- Traders who get out of the market just prior to the crash make the highest profit;

- Traders who leave the market very early make some profit, but forgo much of the profit;

- Traders who stay in the market too long make a loss.

An important feature of the model is that there is both coordination and competition between traders. The coordination feature to burst a bubble is similar to the second generation currency crisis model [6]. Morris and Shin [7] introduce asymmetric information and derive a unique equilibrium by applying the global games approach. Both currency attack models are static in the sense that speculators only decide whether to attack or not. In contrast, the bubble model here assumes there is a dynamic structure. That is to say, the arbitrageurs also need to decide when to exit. Timing is very important, whereby competition is introduced into the model. The preemption motive leads to a unique equilibrium even under symmetric information [8].

\section{The Model}

To illustrate the model, we need to be clear about the subject and the object. The subject is the traders, including both rational traders (or arbitrageurs, speculators, etc.) and irrational traders (or behavioural traders, feedback traders, etc.). However, we can only study the strategy of the rational traders, and derive the equilibrium based on their behaviour. On the other hand, the object is the evolution of the asset price: when it starts to surge and when it starts to crash. The changes in price depend on the interactions between rational and irrational traders. This section will start with a general description of price during bubbles [9].

\section{Price}

The asset price pt during a bubble typically experiences the following four phases.

1. Before the positive shock $(\mathrm{t}::: 0)$, pt grows at the risk-free rate $\mathrm{p}_{\mathrm{t}}=$ ert.

2. After the positive shock but before some random time $t_{0}(0<t$ $::: \mathrm{t}_{0}$ ), pt grows at a higher rate $\mathrm{pt}=$ egt.

a) This higher price is justified by the fundamentals.

b) The random $\mathrm{t} 0$ is exponentially distributed: $\phi(\mathrm{t} 0)=1-\mathrm{e}->\mathrm{t} 0$.

1. After $t_{0}\left(t>t_{0}\right)$, pt continues to grow at $g$, but the fundamental rate is $r$. a) Fundamental Component: $\frac{\mathrm{e}^{\mathrm{gt}} \mathrm{e}^{\mathrm{r}\left(\mathrm{t}-\mathrm{t}_{0}\right)}}{\mathrm{e}^{\mathrm{gt}}}=\mathrm{e}^{-(\mathrm{g}-\mathrm{r})\left(\mathrm{t}-\mathrm{t}_{0}\right)} \equiv 1-\beta$

b) Bubble Component: $1-\mathrm{e}^{-(\mathrm{g}-\mathrm{r}) \mathrm{t}-\mathrm{t}-\mathrm{t})} \equiv \beta$

2. The bubble crashes:

a) either endogenously because more than $\mathrm{K}$ rational traders are aware of the bubble (at $\mathrm{t}+\eta \mathrm{k}$ );

b) or exogenously because the bubble exceeds $\bar{\beta}$-(at $\mathrm{t}+\bar{\tau})$.

The four phases are illustrated in Figure 1.

\section{Traders}

There are two types of traders:

- Irrational traders keep price above its fundamental level;

- Rational traders are sequentially informed of the bubble at some time $\mathrm{t}_{\mathrm{i}}$ after $\mathrm{t}_{0}$.

A key assumption here is asymmetric information. A rational trader does not know how many other traders have been informed of the bubble [10]. Since the traders only differ in when they are aware of the bubble. We identify the trader i by the time when he is informed $t_{i}$. The posterior distribution for $t_{0}$ for a trader $t_{i}$ is assumed to be exponentially distributed:

$$
\phi\left(\mathrm{t}_{0} \mid \mathrm{t}_{\mathrm{i}}\right)=\frac{\mathrm{e}^{\lambda \eta}-\mathrm{e}^{\lambda\left(\mathrm{t}_{\mathrm{i}}-\mathrm{t}_{0}\right)}}{\mathrm{e}^{\lambda \eta}-1}
$$

The conditional distribution of $\mathrm{t}_{0}$ for different traders $\mathrm{i}, \mathrm{j}$ and $\mathrm{k}$ are illustrated in Figure 2.

Due to the dynamic nature of the model, the trader's strategy has two components: the position of the stock (long or short), and the timing of taking the position.

Position: Each rational trader can sell all or part of her stock holding or even go short until she reaches a certain limit where her financial constraint is binding.

- The maximum long position is denoted as 0 and the maximum short position is denoted as 1 (continuous action space).

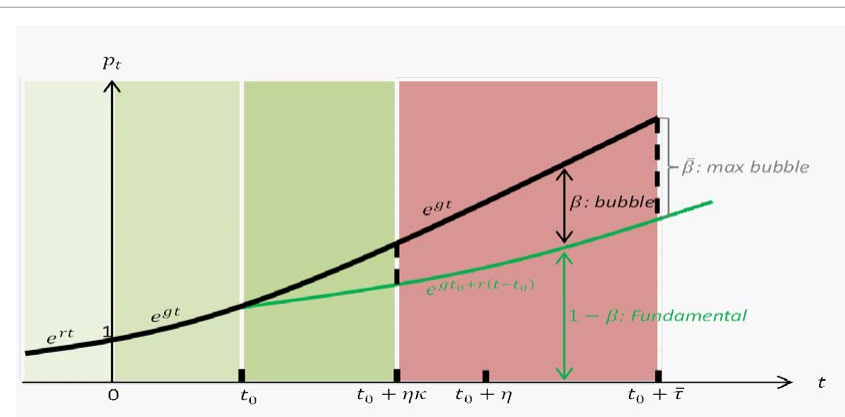

Figure 1: The four phases of price during a typical bubble.

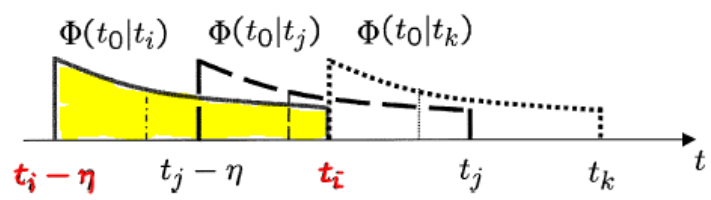

Figure 2: Posterior distribution of $\mathrm{t}_{0}$ 
- Each rational trader may re-enter the market multiple times.

Timing: Each rational trader has to determine when to change her position from long to short.

- The selling pressure/strategy of trader $\mathrm{t}_{\mathrm{i}}$ at time $\mathrm{t}$ is $\sigma\left(\mathrm{t}, \mathrm{t}_{\mathrm{i}}\right)$.

The aggregate selling pressure at time t is $s\left(t, t_{0}\right)=\int_{t_{0}}^{\min \left\{t, t_{0}+n\right\}} \sigma\left(t, t_{i}\right) d t_{i}$.

The crash time given ${ }_{t 0}$ is $T^{*}\left(t_{0}\right)=\inf \left\{t: s\left(t, t_{0}\right) \geq k\right.$ or $\left.t=t_{0}+\bar{\tau}\right\}$.

The posterior belief of crash time is $\Pi\left(t \mid t_{i}\right)=\int_{T^{*}\left(T_{0}\right)<t} d \phi\left(t_{0} \mid t_{i}\right)$.

Like any economic model, the payoff function of the traders needs to be specified to describe their objective. The payoff of trader ti is equal to the expected execution price minus the transaction cost.

- The expected execution price at $\mathrm{t}$ is:

$$
\begin{aligned}
& >\mathrm{e}^{\mathrm{gt}} \text { if } \mathrm{s}\left(\mathrm{t}, \mathrm{t}_{0}\right)<\mathrm{k} ; \\
& >(1-\beta) \mathrm{e}^{\mathrm{gt}} \text { if } \mathrm{s}\left(\mathrm{t}, \mathrm{t}_{0}\right)>\mathrm{k} ; \\
& >(1-\alpha) \times \mathrm{e}^{\mathrm{gt}}+\alpha \times(1-\beta) \mathrm{e}^{\mathrm{gt}} \text { if } \mathrm{s}\left(\mathrm{t}, \mathrm{t}_{0}\right)=\mathrm{k}
\end{aligned}
$$

- The transaction cost at $\mathrm{t}$ is cert.

The general specification of the payoff function is complicated because the trader can re-enter the market several times. For the special case that trader $t_{i}$ remains fully invested in the market until she completely sells out at $t$ and remains out of the market thereafter, trader $t_{i}^{\prime}$ 's expected payoff is:

$$
\int_{t_{i}}^{t} e^{-r s}\left(1-\beta\left(s-T^{*-1}(s)\right)\right) p(s) d \Pi\left(s \mid t_{i}+e^{-r t} p(t)\left(1-\Pi\left(t \mid t_{i}\right)\right)-c .\right.
$$

\section{Equilibrium strategy}

As we said, there are two components in the trader's strategy, position and timing. Therefore, we need to derive both in a trading equilibrium. The following definition, corollary and lemma are related to the position strategy.

Definition 1: A trading equilibrium is defined as a Perfect Bayesian Nash Equilibrium in which whenever a trader's stock holding is less than her maximum, the trader believes that the stock holding of all traders who became aware of the bubble prior to her are also at less than their respective maximum long positions.

Corollary 1: When trader ti sells out her stock holdings, all traders $\mathrm{t}_{\mathrm{j}}\left(\mathrm{t}_{\mathrm{j}}<\mathrm{t}_{\mathrm{i}}\right)$ also have already sold all their shares. ("cut-off property")

Lemma 1: In equilibrium, a trader is either fully invested in the market $\sigma\left(\mathrm{t}_{\mathrm{i}} \mathrm{t}_{\mathrm{i}}\right)=0$, or at her maximum short position $\sigma\left(\mathrm{t}, \mathrm{t}_{\mathrm{i}}\right)=1$. There is no partial purchases or sell outs.

The followings are related to the timing strategy.

Definition 2: The function $\mathrm{T}\left(\mathrm{t}_{\mathrm{i}}\right)=\inf \left\{\mathrm{t} \sigma\left(\mathrm{t}, \mathrm{t}_{\mathrm{i}}\right)>0\right\}$ denotes the first instant at which trader ti sells any of her shares.

Corollary 2: The bubble bursts at $\mathrm{T}^{*}=\min \left\{\mathrm{T}\left(\mathrm{t}_{0}+\eta \mathrm{k}\right), \mathrm{t}_{0}+\bar{\tau}\right\}$.

Lemma 2: In equilibrium, trader ti believes at time $\mathrm{T}(\mathrm{ti})$ that at most a mass $\mathrm{K}$ of traders became aware of the bubble prior to her. ("preemption")

To summarise the equilibrium strategy, trader $t_{i}$ maintains the maximum short position for all $t \geq T\left(t_{i}\right)$, until the bubble bursts ("trigger strategy"). In the trigger strategy, all rational traders' strategies are corner solution.

\section{Equilibrium crash time}

The interaction among traders may lead to crash endogenously or the bubble will crash exogenously. The following proposition describes the condition of endogenous crash.

Under the condition

$\frac{\lambda}{1-\mathrm{e}^{-\lambda \eta \kappa}} \leq \frac{\mathrm{g}-\mathrm{r}}{\bar{\beta}}$

There exists a unique trading equilibrium, where all traders sell out in, $\tau^{1}=\bar{\tau}-\frac{1}{\lambda} \ln \left(\frac{\mathrm{g}-\mathrm{r}}{\mathrm{g}-\mathrm{r}-\lambda \bar{\beta}}\right)<\bar{\tau}$

Periods after they become aware of the bubble and stay out of the market thereafter.

For all $t_{0}$, the bubble bursts for exogenous reasons precisely when it reaches its maximum possible size $/ \bar{\beta}$. The intuition behind this proposition is that rational traders never burst the bubble if the dispersion of opinion $(\eta)$ and the absorption capacity of irrational traders are sufficiently large.

Alternatively, the following proposition describes the reverse case when there is an exogenous crash.

- Under the condition

$\frac{\lambda}{1-\mathrm{e}^{-\lambda \eta \kappa}}>\frac{\mathrm{g}-\mathrm{r}}{\bar{\beta}}$,

There exists a unique trading equilibrium, where trader $t_{i}$ with $t_{i} 2$ : TK sells out in,

$$
\tau^{*}=\beta^{1}\left(\frac{\frac{\mathrm{g} r}{1 \mathrm{e}^{-\lambda \eta \kappa}}}{\bar{r}}\right)
$$

Periods after they become aware of the bubble and stays out of the market thereafter. All traders $t_{i}$ with $t_{i}<\eta k$ sell out at $\eta \mathrm{k}+\mathrm{T}^{*}$.

The bubble bursts when

$$
\beta^{*}=\frac{1-\mathrm{e}^{-\lambda \eta \kappa}}{\lambda}(\mathrm{g}-\mathrm{r})
$$

The intuition is that the maximum relative bubble size $\beta^{*}$ increases as the dispersion of opinions $(\eta)$ and the absorption capacity of the irrational traders increase.

\section{Application}

The model proposed by Abreu and Brunnermeier [1] creatively explains why there is a bubble, i.e. when the asset is overpriced. However, it assumes that after the bubble crashes, the asset price gets back to the fundamental level. This is obviously not true in data. More often, what we observe in the financial market is that after a crash, the asset prices tend to overshoot, falling far below the fundamental level. It leads to persistent recessions or even depression as in the 1930s.

This overreaction in both upturns and downturns over the business cycles can be explained by applying the bubble theory too. In fact, if we assume the price after crash return to the fundamental level, it is inconsistent to the assumption of existence of irrational traders. The 
explaining power of this model can be and should be extended to explaining the overshooting crash in addition to bubble.

Instead of assuming that the asset price returns to fundamental level after crash, we consistently assume the panic in the fi nancial market will make the irrational traders think the asset price is much lower than the fundamental level. Assume the wrong growth rate is now $g^{\prime}<r$, lower than the true rate. The asset price will not stop dropping at $\mathrm{e}^{\mathrm{gt} t+\mathrm{r}(\mathrm{t}-\mathrm{t})}$, but at $\mathrm{p}_{\mathrm{t}}=\mathrm{e}^{\mathrm{gt0}}+\mathrm{g}^{\prime(\mathrm{t} t \mathrm{t})}$ and this will continue.

Assume $t_{1}$ is the time when the first rational trader become aware of the overshooting. Again, $t_{1}$ is a random variable following an exponential distribution. The same dispersion of opinion $\mathrm{T}$ exists among all the rational traders. Only when $\mathrm{k}$ traders collectively stop shorting the asset, the price will stop falling and return towards the fundamental value. This starts another cycle of bubble, just like business cycles in macroeconomics, but the cycles in financial market is more drastic and frequent. This extension enables the model to provide a symmetric explanation of the bubbles and overshooting crash.

\section{Conclusion}

The backward induction argument rules out bubbles from the terminal date, but these classical models assume common knowledge. Bubble can exist if there is a dispersion of opinions (heterogenous traders). In this case, existence of bubble is mutual knowledge, but not common knowledge because they do not know if the others know. The rational trader tries to "ride the bubble" to earn some profit before the bubble crashes. Therefore, the timing is a very important element in the strategy.

If the dispersion of opinion and the absorption of irrational traders are large, then there will be an exogenous crash. If the dispersion of opinion and the absorption of irrational traders are small, then there will be an endogenous crash.

The model can be extended to explaining the overshooting behaviour in both upturns (bubbles) and downturns in financial market.
Expectation drives the price to fluctuate around the fundamental value but never stays, because the behavioural traders provide the opportunities for rational arbitrageurs to "ride the bubble" or buying "at rock bottom". However, the specification of this model implies the irrational traders are always losers, though not all rational traders are always winners. A more general model along this consideration could add in a distribution or dispersion of opinions within the irrational traders too. For example, some irrational traders are over-optimistic (those supporting the bubbles), while some are over-pessimistic (those supporting the overshooting crash). There are also a continuum of irrational traders between the two extremes, just like the dispersion of opinions among the rational traders. Under this generalised assumption, we can then explain more fluctuations of price behaviour, such as non-monotonic fluctuations in a bubble and double bottoms.

\section{References}

1. Abreu D, Brunnermeier B (2003) Bubbles and Crashes. Econometrica 71: 173-204.

2. Santos M, Woodford M (1997) Rational Asset Pricing Bubbles. Econometrica 65: 19-57.

3. Allen F, Morris S, Postlewaite A (1993) Finite Bubbles with Short Sale Constraints and Asymmetric Information. Journal of Economic Theory 61: 206-229.

4. Allen F, Gorton G (1993) Churning Bubbles. Review of Economic Studies 60: 813-836.

5. DeLong JB, Shleifer A, Summers L H, Waldmann R J (1990) Noise Trader Risk in FInancial Markets. Journal of Finance 53: 1839-1885.

6. Obstfeld M (1996) Models of Currency Crises with Self-Fulfilling Features. EuropeanEconomicReview 40:1037-1047.

7. Morris S, Shin H (1998) Unique Equilibrium in a Model of Self- Fullfilling Currency Attacks. American Economic Review 88: 587-596.

8. Brunnermeier MK (2000) Asset Pricing under Asymmetric Information: Bubbles, Crashes, Technical Analysis and Herding. Oxford: Oxford University Press.

9. Hirshleifer D (2001) Investor Psychology. Journal of Finance 56: 1533-1597.

10. Tirole J (1982) On the Possibility of Speculation under Rational Expectations Econometrica 50: 1163-1182. 